\title{
PENGARUH PERCAMPURAN AIR TERHADAP OKSIGEN TERLARUT DI SEKITAR KARAMBA JARING APUNG, WADUK CIRATA, PURWAKARTA, JAWA BARAT
}

\author{
Hefni Effendi' ${ }^{1}$ Enan M. Adiwilaga², Agustina Sinuhaji ${ }^{2}$ \\ (Diterima tanggal: 2 Juni 2011; Disetujui tangal: 2 November 2011)
}

\begin{abstract}
Research was performed at waters nearby floating cage culture, Cirata Reservoir, Purwakarta, West Java. Research aims is to determine the variation of dissolved oxygen availability through the mixing of water masses taken from several depths. The range of average DO decreased with increasing depth, namely $0.3-0.5 \mathrm{mg} / \mathrm{l}$ (bottom) and 8.0 $-8.4 \mathrm{mg} / \mathrm{l}$ (surface). Type of vertical oxygen distribution of Cirata waters was clinograde. Euphotic zone reached the depth of $3.81 \mathrm{~m}$. The average range of DO at treatment 1 (meromictic, depth $12 \mathrm{~m}$ ) was $7.00-7.41 \mathrm{mg} / \mathrm{l}$. The average range of DO at treatment 2 (meromictic, depth $24 \mathrm{~m}$ ) was $5.28-5.48 \mathrm{mg} / \mathrm{l}$. The average range of DO at treatment 3 (holomictic, depth $\mathrm{m}$ ) was $2.44-2.54 \mathrm{mg} / \mathrm{l}$. If water column mixing (meromictic depth $12 \mathrm{~m}$ and 24 $\mathrm{m}$ ) occurs, fish culture will still be survive, since DO is $>5 \mathrm{mg} / \mathrm{l}$. However, whole water column mixing (holomictic depth $42 \mathrm{~m}$ ) will result in almost anoxic DO, consequently jeopardize fish culture at floating cage.
\end{abstract}

Keywords: dissolved oxygen, reservoir, floating cage, Cirata Resevoir, Purwakarta

\begin{abstract}
ABSTRAK
Penelitian dilakukan di sekitar keramba apung Waduk Cirata (KJA), Purwakarta, Jawa Barat. Penelitian bertujuan untuk mengetahui fluktuasi ketersediaan oksigen terlarut dalam perairan, melalui percampuran massa air yang diambil dari beberapa kedalaman. Konsentrasi DO di lokasi KJA di Waduk Cirata menurun seiring bertambahnya kedalaman dengan kisaran rata-rata adalah 0,3 - 0,5 mg/l (lapisan dasar) hingga 8,0 - 8,4 mg/l (permukaan). Distribusi vertikal oksigen terlarut menggambarkan tipe perairan clinograde. Kedalaman zona eufotik mencapai 3,81 m. Terdapat variasi ketersediaan oksigen terlarut dari pencampuran massa air meromictic dan holomictic. Pada perlakuan 1 (meromictic hingga $12 \mathrm{~m}$ ) nilai rata-rata DO yaitu 7,00 - 7,41 mg/l. Perlakuan 2 (meromictic hingga 24 m) nilai rata-rata DO 5,28 - 5,48 mg/l. Perlakuan 3 (holomictic hingga $42 \mathrm{~m}$ ) memiliki nilai rata-rata DO sebesar 2,44 - 2,84 mg/l. Jika terjadi percampuran meromictic hingga kedalaman $12 \mathrm{~m}$ dan $24 \mathrm{~m}$ maka kegiatan budidaya ikan masih dianggap layak, karena nilai DO $>5 \mathrm{mg} / \mathrm{l}$. Akan tetapi, pencampuran holomictic mengakibatkan DO melewati ambang batas, sehingga tidak dapat menopang budidaya perikanan.
\end{abstract}

Kata Kunci: oksigen terlarut, waduk, jaring apung, Waduk Cirata, Purwakarta

\section{PENDAHULUAN}

Ekosistem waduk merupakan perpaduan antara ekosistem lacustrine (lentik) dan riverine (lotik), karena waduk merupakan badan perairan yang dibuat dengan membendung aliran sungai, sehingga menenggelamkan daerah aliran sungai di sekitarnya. Karakteristik fisik, kimia, dan biologis waduk berbeda dari sungai asalnya yang dibendung, Waduk dapat berfungsi sebagai pembangkit tenaga listrik, irigasi pertanian, sarana transportasi, tempat rekreasi, sumber air minum, dan pusat budidaya ikan keramba jaring apung ${ }^{(1,2,3,4)}$.

Salah satu waduk di DAS Citarum adalah

\footnotetext{
${ }^{1}$ Pusat Penelitian Lingkungan Hidup (PPLH), IPB, Darmaga, Bogor. Telp. 0251-8621262, Fax. 0251-8622134 Email: hefni_effendi@yahoo.com

${ }^{2}$ Departemen Manajemen Sumberdaya Perairan, Fakultas Perikanan dan Ilmu Kelautan, IPB, Darmaga, Bogor. Telp/Fax 0251-8622932
} 
Waduk Cirata. Selain sebagai pembakit tenaga listrik, waduk ini juga dimanfaatkan untuk budidaya ikan konsumsi dengan mengunakan keramba apung. Konsekuensinya, saat ini Waduk Cirata mengalami masalah serius terkait dengan penurunan kualitas air yang disebabkan oleh bahan organik dari sisa pakan ikan, limbah dosmestik, dan limbah industri.

Banyaknya jumlah KJA (Keramba Jaring Apung) yang berada di Waduk Cirata sangat berpengaruh terhadap kualitas air. Daya dukung Waduk Cirata untuk KJA adalah 2700 petak. Jumlah KJA pada Waduk Cirata mengalami peningkatan pesat. Pada tahun 1988 berjumlah 74 petak, lalu menjadi 17.477 petak pada tahun 1999 , pada tahun 2000 jumlahnya mencapai 28.738, dan pada tahun 2008 jumlah unit KJA pada Waduk Cirata mencapai 53.100 unit ${ }^{(5)}$, sehingga telah jauh melampui batas daya dukung ${ }^{(6)}$. Perubahan kualitas air di waduk bukan disebabkan terutama oleh kegiatan hidroelektrik tapi akibat kegiatan lainnya ${ }^{(7)}$. Kualitas air permukaan lebih dipengaruhi oleh karakteristik geologi, kegiatan pertanian, dan domestik di sekitarnya ${ }^{(8)}$.

Pertambahan KJA dari tahun ke tahun dapat menimbulkan masalah yang berasal dari pakan. Pakan merupakan bahan organik. Pakan yang tidak termakan oleh ikan, akan mengalami perombakan menjadi bahan anorganik. Produk dari perombakan bahan organik ini tidak hanya berupa nutrien yang menyebabkan terjadinya eutrofikasi perairan. Tetapi juga berupa gas-gas beracun seperti $\mathrm{NH}_{3}$ dan $\mathrm{H}_{2} \mathrm{~S}$ yang terakumulasi di dasar waduk. Gas beracun tersebut merupakan hasil proses dekomposisi dalam kondisi anaerob $(9,10)$.

Apabila terjadi pembalikan massa air ke permukaan (umbalan/overturn) akan membahayakan, bahkan dapat mengakibatkan kematian massal ikan yang dibudidayakan. Untuk memahami ini fluktuasi karakteristik kualitas air baik secara spatial maupun temporal, perlu dipantau secara kontinyu ${ }^{(11,12)}$.

Defisit oksigen di lapisan hipolimnion diduga menjadi penyebab kematian massal ikan saat terjadi umbalan. Oleh karena itu, untuk mengetahui fluktuasi ketersediaan oksigen terlarut dalam perairan, perlu dilakukan penelitian terhadap pola distribusi keberadaan oksigen terlarut di lokasi KJA Waduk Cirata melalui percampuran massa air yang dianggap sebagai kejadian umbalan.

\section{METODE PENELITIAN}

Penelitian dilakukan pada kawasan perikanan keramba jaring apung (KJA) di Waduk Cirata Purwakarta, Jawa Barat (Gambar 1). Kegiatan penelitian berlangsung pada bulan Juli dan September 2009. Sampel air dianalisis di Laboratorium Produktivitas dan Lingkungan Perairan (Proling) yang telah terakreditasi Komite Akreditasi Nasional (KAN), Departemen Manajemen Sumberdaya Perairan, Fakultas Perikanan dan Ilmu Kelautan, Institut Pertanian Bogor.

Stasiun pengamatan berupa daerah KJA paling padat dengan KJA sedang beroperasi dan yang paling lama memelihara ikan. Pengamatan kualitas air dilakukan pada dua lokasi. 


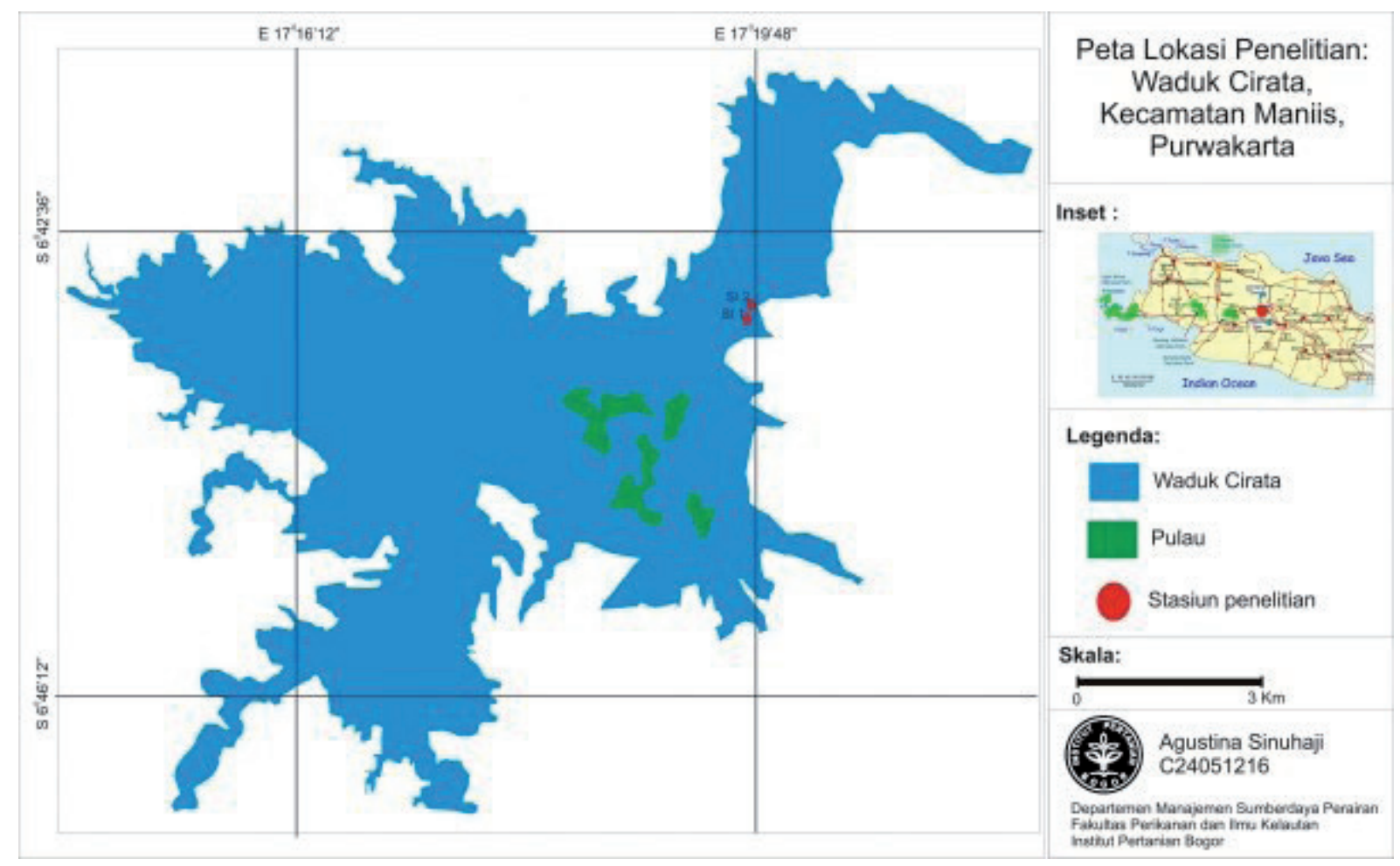

Gambar 1. Lokasi penelitian di sekitar keramba jaring apung, Waduk Cirata, Purwakarta, Jawa Barat.

Pada penelitian pendahuluan dilakukan pengukuran oksigen terlarut (DO) dengan interval 2 sampai $6 \mathrm{~m}$ dari permukaan, bertujuan untuk mendapatkan pola sebaran vertikal oksigen terlarut (Tabel 1). Dari sebaran vertikal oksigen terlarut diperoleh keterwakilan area dan titik-titik kedalaman pengambilan contoh air. Selanjutnya ditentukan 3 perlakuan melalui pencampuran massa air dari keterwakilan area pada beberapa kedalaman. 
Table 1. Konsentrasi oksigen terlarut rata-rata pada penelitian pendahuluan.

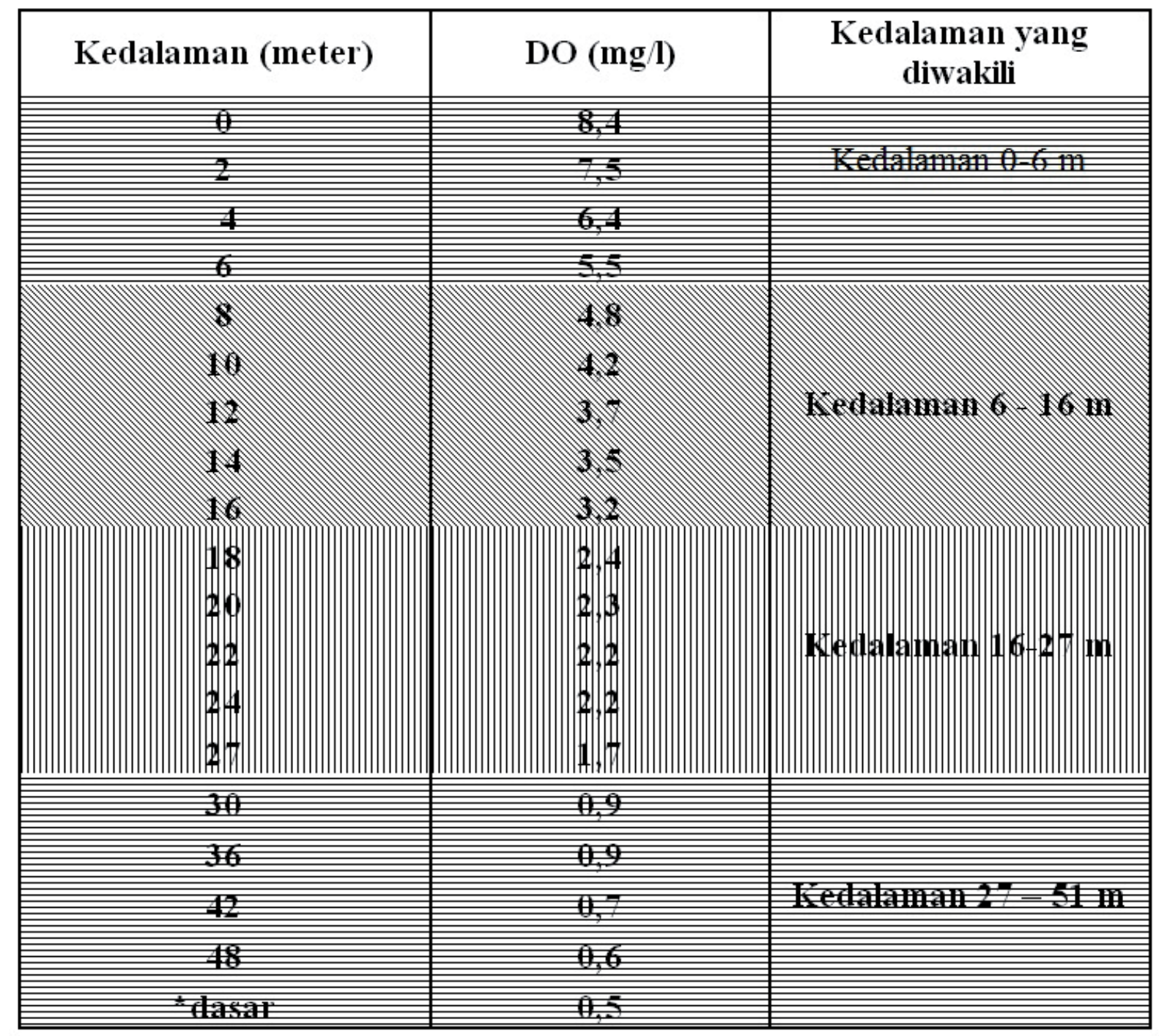

Perlakuan 1 merupakan pencampuran air sebagian (meromictic) dari kedalaman 2 dan $12 \mathrm{~m}$. Perlakuan 2 adalah pencampuran massa air sebagian (meromictic) dari kedalaman 2, 12, dan $24 \mathrm{~m}$. Perlakuan 3 adalah pencampuran massa air sempurna (holomictic) dari kedalaman 2, 12, 24, dan $42 \mathrm{~m}$. Komposisi contoh air (Tabel 2) yang dicampurkan menggunakan rumus berikut.

$$
\text { Komposisi }=\frac{\text { jumlah kedalaman yang terwakili }}{\text { jumlah kedalaman total }} \times \text { volume botol }
$$


Table2. Komposisi air dari setiap kedalaman yang mewakili.

\begin{tabular}{|c|c|c|c|c|}
\hline \multirow{3}{*}{ Perlakuan } & $\begin{array}{c}\text { Kedalaman } \\
\text { (meter) }\end{array}$ & $\begin{array}{c}\text { Volume sampel } \\
\text { untuk } \\
\text { DO (ml) }\end{array}$ & $\begin{array}{c}\text { Volume sampel } \\
\text { untuk } \\
\text { Amonia (m) }\end{array}$ & $\begin{array}{c}\text { Volume sampel } \\
\text { untuk } \\
\text { Sulfida dan pH } \\
\text { (mI) }\end{array}$ \\
\hline \multirow{4}{*}{1} & 2 & 46,88 & 60 & 150 \\
\cline { 2 - 5 } & 12 & 78,12 & 40 & 100 \\
\cline { 2 - 5 } & $\begin{array}{c}\text { Total volume } \\
\text { botol }\end{array}$ & 125 & 100 & 250 \\
\hline \multirow{4}{*}{2} & 2 & 27,78 & 22,22 & 55,56 \\
\cline { 2 - 5 } & 12 & 46,29 & 37,04 & 92,59 \\
\cline { 2 - 5 } & 24 & 50,93 & 40,74 & 101,85 \\
\hline \multirow{4}{*}{3} & $\begin{array}{c}\text { Total volume } \\
\text { botol }\end{array}$ & 125 & 100 & 250 \\
\cline { 2 - 5 } & 2 & 14,71 & 11,76 & 29,41 \\
\cline { 2 - 5 } & 12 & 24,51 & 19,61 & 49,02 \\
\cline { 2 - 5 } & 24 & 26,96 & 21,57 & 117,65 \\
\cline { 2 - 5 } & 42 & 58,82 & 47,06 & 250 \\
\hline
\end{tabular}

\section{HASIL DAN PEMBAHASAN}

\section{Distribusi vertikal DO, suhu, dan pH}

Nilai rata-rata oksigen terlarut (Dissolved Oxygen/DO) dari permukaan hingga dasar perairan berkisar $0,5-8,4 \mathrm{mg} / 1$ pada stasiun 1 , dan $0,3-8,0 \mathrm{mg} / 1$ pada stasiun 2. Konsentrasi rata-rata DO terbesar pada stasiun 1 dan 2 terdapat di permukaan yakni 8,4 dan $8,0 \mathrm{mg} / \mathrm{l}$. Konsentrasi rata-rata DO terendah pada kedua stasiun terdapat pada sekitar dasar (51 m) yaitu 0,5 mg/l (stasiun 1) dan 0,3 mg/1 (stasiun 2). DO pada lapisan hipolimnion bisa sangat rendah atau terkadang anoxic (tak ada oksigen) (7). Kondisi oksigen mencapai titik jenuh pada lapisan permukaan dengan nilai saturasi pada stasiun 1 adalah $112,38 \%$ dan $107,67 \%$ pada stasiun 2

Rendahnya DO di sekitar dasar karena adanya dekomposisi bahan organik, terutama sisa pakan, yang memanfaatkan oksigen di dasar perairan. Proses fotosintesis yang menghasilkan oksigen di lapisan permukaan mengakibatkan tingginya kadar oksigen di permukaan ${ }^{(13)}$. Berdasarkan nilai kecerahan diperoleh kedalaman zona eufotik hingga 3,81 m pada stasiun 1 , dan $3,75 \mathrm{~m}$ pada stasiun 2 .

Tipe distribusi DO di waduk ini termasuk dalam tipe clinograde yang biasanya terjadi pada danau yang produktif (eutrofik) dengan kandungan unsur hara dan bahan organik yang tinggi ${ }^{(10)}$. Apabila dibandingkan dengan baku mutu DO ( $\geq 3 \mathrm{mg} / \mathrm{l})$ berdasarkan Peraturan Pemerintah Nomor 82 Tahun 2001 kelas III, kedalaman 0 - 16 m pada kedua stasiun memenuhi baku mutu bagi kegiatan perikanan, sedangkan dari kedalaman $18 \mathrm{~m}$ hingga dasar konsentrasi oksigen terlarut sudah tidak memenuhi baku mutu (Tabel 3). DO menjadi indikator bagi kualitas air, status ekologi, produktivitas, dan kesehatan dari suatu waduk $^{(3)}$. 
Table3. Distribusi vertikal DO, suhu, dan $\mathrm{pH}$.

\begin{tabular}{|c|c|c|c|c|c|c|}
\hline \multirow{2}{*}{ Kedalaman } & \multicolumn{2}{|c|}{ DO (mg/l) } & \multicolumn{2}{c|}{ Suhu $\left({ }^{0} \mathrm{C}\right)$} & \multicolumn{2}{c|}{ pH } \\
\cline { 2 - 7 } & $\mathbf{1}$ & $\mathbf{2}$ & $\mathbf{1}$ & $\mathbf{2}$ & $\mathbf{1}$ & $\mathbf{2}$ \\
\hline 0 & 8,4 & 8,0 & 30,7 & 30,5 & 6,98 & 7,19 \\
\hline 2 & 7,5 & 7,6 & 30,3 & 30,3 & 6,96 & 7,19 \\
\hline 4 & 6,4 & 6,9 & 30,1 & 30,0 & 6,96 & 7,15 \\
\hline 6 & 5,5 & 6,2 & 29,8 & 29,7 & 6,94 & 7,11 \\
\hline 8 & 4,8 & 6,6 & 29,4 & 29,4 & 6,93 & 7,04 \\
\hline 10 & 4,2 & 5,4 & 29,2 & 29,1 & 6,93 & 7,01 \\
\hline 12 & 3,7 & 4,2 & 28,7 & 28,8 & 6,93 & 6,97 \\
\hline 14 & 3,5 & 3,9 & 28,7 & 28,6 & 6,90 & 6,95 \\
\hline 16 & 3,2 & 3,5 & 28,5 & 28,4 & 6,90 & 6,93 \\
\hline 18 & 2,4 & 2,6 & 28,2 & 28,4 & 6,87 & 6,91 \\
\hline 20 & 2,3 & 2,5 & 27,7 & 28,1 & 6,79 & 6,89 \\
\hline 22 & 2,2 & 2,4 & 27,6 & 27,9 & 6,77 & 6,87 \\
\hline 24 & 2,2 & 2,1 & 27,6 & 27,6 & 6,70 & 6,85 \\
\hline 27 & 1,7 & 1,6 & 27,5 & 27,2 & 6,69 & 6,82 \\
\hline 30 & 0,9 & 1,4 & 26,9 & 27,1 & 6,68 & 6,76 \\
\hline 36 & 0,9 & 1,1 & 26,7 & 26,8 & 6,67 & 6,64 \\
\hline 42 & 0,7 & 0,8 & 26,4 & 26,5 & 6,66 & 6,59 \\
\hline 48 & 0,6 & 0,5 & 26,2 & 26,2 & 6,65 & 6,52 \\
\hline * dasar & 0,5 & 0,3 & 26,0 & 26,0 & 6,52 & 6,50 \\
\hline Baku mutu & & & & $28 \pm 3$ & & $6-9$ \\
\hline
\end{tabular}

Keterangan : *kedalaman maksimum di lokasi pengamatan adalah 51 meter

Rendahnya kadar oksigen terlarut berkaitan erat dengan tingginya beban pencemaran BOD yang masuk ke waduk yakni sekitar 148.782 ton organik/tahun atau 425 ton organik/hari (14).

Kisaran suhu pada kedua stasiun berturutturut adalah $26,0-30,7{ }^{\circ} \mathrm{C}$ dan $26,0-30,5^{\circ} \mathrm{C}$ (Tabel 3). Suhu tertinggi rata-rata terdapat di permukaan yaitu $30,7^{\circ} \mathrm{C}$ pada stasiun 1 dan $30,5{ }^{\circ} \mathrm{C}$ pada stasiun 2 . Ketika pengamatan tidak diperoleh lapisan termoklin yaitu lapisan air yang mengalami penurunan suhu cukup besar yakni lebih dari $1{ }^{\circ} \mathrm{C} / \mathrm{m}^{(15)}$, sehingga kemungkinan adanya stratifikasi sangatlah kecil. Pola sebaran vertikal suhu yang diperoleh di lokasi pengamatan relatif sama dengan pengamatan yang dilakukan oleh Prihadi (2005) yaitu tidak ditemukannya lapisan termoklin ${ }^{(16)}$.

Nilai $\mathrm{pH}$ rata-rata tertinggi terdapat di permukaan yaitu 6,98 (stasiun 1) dan 7,19 (stasiun 2). $\mathrm{pH}$ terendah terdapat di dasar yaitu 6,52 (stasiun 1) dan 6,50 (stasiun 2). Berdasarkan Peraturan Pemerintah No. 82 
tahun 2001 kelas III, nilai pH dan suhu yang diperoleh dari kedua stasiun masih memenuhi baku mutu yang dianjurkan bagi kegiatan perikanan. Kisaran $\mathrm{pH}$ yang dianjurkan adalah 6 - 9, sedangkan suhu $28 \pm 3{ }^{\circ} \mathrm{C}$.

\section{Kualitas air dari hasil pencampuran massa air}

Nilai DO rata-rata tertinggi terdapat pada perlakuan 1 yaitu 7,41 (stasiun 1 ) dan 7,00 $\mathrm{mg} / \mathrm{l}$ (stasiun 2). Pada perlakuan 2 konsentrasi DO rata-rata pada kedua stasiun adalah 5,48 dan 5,28 mg/l. Nilai DO rata-rata pada perlakuan 3 di kedua stasiun berturut-turut adalah 2,84 dan 2,44 mg/l. Perlakuan 1 dan 2 di kedua stasiun memiliki nilai DO yang dianggap masih baik bagi kegiatan perikanan, karena nilai DO tidak kurang dari $5 \mathrm{mg} / \mathrm{l}^{(17)}$. Pada perlakuan 3 nilai DO yang rendah tidak bagus bagi kepentingan perikanan, karena dapat mengganggu proses metabolisme dan pertumbuhan ikan (Tabel 4).

Nilai suhu rata-rata tertinggi pada stasiun 1 dan 2 terdapat pada perlakuan 1 (percampuran kedalaman $2 \mathrm{~m}$ dan $12 \mathrm{~m}$ ). Selanjutnya nilai suhu rata-rata dari pencampuran kedalaman 2, 12, dan 24 meter (perlakuan 2) adalah 28,1 ${ }^{0} \mathrm{C}$ pada stasiun 1 dan $28,3{ }^{\circ} \mathrm{C}$. Suhu rata-rata dari pencampuran air di kedalaman 2, 12, 24, dan 42 meter (perlakuan 3) adalah 26,8 dan $26,6{ }^{\circ} \mathrm{C}$ pada stasiun 1 dan 2 .

Hal tersebut menunjukkan bahwa dari perlakuan 1 sampai 3 nilai suhu cenderung menurun karena perlakuan 3 merupakan hasil pencampuran dari 4 kedalaman yang berbeda termasuk kedalaman di dasar dengan suhu yang rendah.

Nilai $\mathrm{pH}$ rata-rata tertinggi pada perlakuan 1 adalah 6,93 (stasiun 1) dan 7,10 (stasiun 2). Nilai $\mathrm{pH}$ rata-rata perlakuan 2 adalah 6,79 (stasiun 1) dan 6,90 (stasiun 2). Nilai pH ratarata pada perlakuan 3 di kedua stasiun adalah 6,62 dan 6,60. Hal tersebut menunjukkan bahwa dari perlakuan 1 sampai 3 nilai $\mathrm{pH}$ cenderung menurun karena perlakuan 3 merupakan hasil pencampuran dari 4 kedalaman yang berbeda termasuk kedalaman di dasar dengan $\mathrm{pH}$ yang cenderung rendah (asam) sehingga pada perlakuan 3 nilai $\mathrm{pH}$ yang diperoleh lebih kecil dibandingkan dengan nilai $\mathrm{pH}$ pada perlakuan 1 dan 2 .

Kondisi tersebut menunjukkan bahwa jika terjadi pencampuran air sempurna, maka perairan akan cenderung bersifat lebih asam. Namun demikian, seluruh perlakuan

Tabel 4. Karakteristik kualitas air dari pencampuran massa air.

\begin{tabular}{|c|c|c|c|c|c|c|c|c|c|c|c|c|c|c|c|c|}
\hline \multirow{2}{*}{ Stasiun } & \multirow{2}{*}{ Ulangan } & \multicolumn{5}{|c|}{ Perlakuan 1} & \multicolumn{5}{|c|}{ Perlakuan 2} & \multicolumn{5}{|c|}{ Perlakuan 3} \\
\hline & & $\begin{array}{c}\mathrm{DO} \\
(\mathrm{mg} / \mathrm{l})\end{array}$ & $\begin{array}{l}\text { Suhu } \\
\left({ }^{\circ} \mathrm{C}\right)\end{array}$ & $\mathrm{pH}$ & $\begin{array}{c}\mathrm{NH}_{3} \\
(\mathrm{mg} / \mathrm{l})\end{array}$ & $\begin{array}{c}\mathrm{H}_{2} \mathrm{~S} \\
(\mathrm{mg} / \mathrm{I})\end{array}$ & $\begin{array}{c}\mathrm{DO} \\
(\mathrm{mg} / \mathrm{l})\end{array}$ & $\begin{array}{l}\text { Suhu } \\
\left({ }^{\circ} \mathrm{C}\right)\end{array}$ & $\mathrm{pH}$ & $\begin{array}{c}\mathrm{NH}_{3} \\
(\mathrm{mg} / \mathrm{l})\end{array}$ & $\begin{array}{c}\mathrm{H}_{2} \mathrm{~S} \\
(\mathrm{mg} / \mathrm{l})\end{array}$ & $\begin{array}{c}\mathrm{DO} \\
\mathrm{mg} / \mathrm{I})\end{array}$ & $\begin{array}{l}\text { Suhu } \\
\left({ }^{\circ} \mathrm{C}\right)\end{array}$ & $\mathrm{pH}$ & $\begin{array}{c}\mathrm{NH}_{3} \\
(\mathrm{mg} / \mathrm{l})\end{array}$ & $\begin{array}{c}\mathrm{H}_{2} \mathrm{~S} \\
(\mathrm{mg} / \mathrm{l})\end{array}$ \\
\hline \multirow{3}{*}{1} & 1 & 7,51 & 29,4 & 6,94 & 0,0081 & 0,0541 & 5,48 & 28,0 & 6,80 & 0,0087 & 0,3451 & 3,04 & 26,7 & 6,60 & 0,0116 & 1,4586 \\
\hline & 2 & 7,31 & 29,6 & 6,91 & 0,0053 & 0,0571 & 5,48 & 28,1 & 6,78 & 0,0080 & 0,3560 & 2,64 & 26,9 & 6,63 & 0,0171 & 2,1485 \\
\hline & Rata 2 & 7,41 & 29,5 & 6,93 & 0,0067 & 0,0556 & 5,48 & 28,1 & 6,79 & 0,0083 & 0,3506 & 2,84 & 26,8 & 6,62 & 0,0144 & 1,8036 \\
\hline \multirow{3}{*}{2} & 1 & 6,90 & 29,6 & 7,08 & 0,0270 & 0,0367 & 5,08 & 28,2 & 6,89 & 0,0290 & 0,3009 & 2,64 & 26,5 & 6,58 & 0,0308 & 0,3009 \\
\hline & 2 & 7,10 & 29,6 & 7,12 & 0,0275 & 0,0673 & 5,48 & 28,3 & 6,90 & 0,0267 & 0,2734 & 2,23 & 26,7 & 6,61 & 0,0292 & 0,2734 \\
\hline & Rata 2 & 7,00 & 29,6 & 7,10 & 0,0273 & 0,0673 & 5,28 & 28,3 & 6,90 & 0,0278 & 0,2871 & 2,44 & 26,6 & 6,60 & 0,0300 & 1,5876 \\
\hline
\end{tabular}

Keterangan:

Perlakuan 1 = Pencampuran kedalaman 2 dan 12 meter

Perlakuan 2 = Pencampuran kedalaman 2, 12, dan 24 meter

Perlakuan 3 = Pencampuran kedalaman 2, 12, 24 dan 42 meter 
menunjukkan bahwa nilai $\mathrm{pH}$ yang diperoleh masih layak bagi kegiatan perikanan. Kisaran $\mathrm{pH}$ yang sesuai untuk kepentingan biota air adalah $6,5-8,5^{(17)}$.

Nilai amonia rata-rata tertinggi di kedua stasiun terdapat pada perlakuan 3 yakni $0,0067 \mathrm{mg} / 1$ (stasiun 1) dan 0,0273 mg/l (stasiun 2). Nilai amonia rata-rata perlakuan 2 di kedua stasiun adalah $0,0083 \mathrm{mg} / \mathrm{l}$ dan $0,0278 \mathrm{mg} / 1$. Amonia rata-rata pada perlakuan 3 adalah 0,0144 mg/l (stasiun 1) dan 0,0300 mg/l (stasiun 2). Dari perlakuan 1 sampai 3, nilai amonia bebas yang diperoleh cenderung meningkat.

Secara umum kadar ammonia ini relatif rendah, karena baku mutu membolehkan hingga 0,5 mg/l (PP No. 82 tahun 2001 kelas I). Kadar ammonia di Pipestem Reservoir sebesar $0,272 \mathrm{mg} / \mathrm{l}^{(18)}$. kadar ammona di Ibitite Reservoir, Brasil, sekitar 0,288 mg/1 ${ }^{(19)}$. Konsentrasi sulfida rata-rata tertinggi terdapat pada perlakuan 3 yakni 1,8036 mg/1 (stasiun 1) dan 1,5876 mg/l (stasiun 2). Sulfida rata-rata kedua stasiun dari perlakuan 2 adalah 0,3506 $\mathrm{mg} / \mathrm{l}$ dan $0,2871 \mathrm{mg} / \mathrm{l}$. Sulfida rata-rata pada perlakuan 1 di kedua stasiun adalah 0,0556 $\mathrm{mg} / \mathrm{l}$ dan 0,0673 mg/l.

Dari perlakuan 1 sampai 3, nilai sulfida dan amonia cenderung meningkat. Hal ini berhubungan dengan proses dekomposisi bahan organik sisa pakan, yang banyak mengkonsumsi oksigen, dan konsekuensinya dapat menghabiskan oksigen (anoksik). Pada kondisi anoksik, proses dekomposisi akan menghaslkan gas amonia $\left(\mathrm{NH}_{3}\right)$ dan sulfida $\left(\mathrm{H}_{2} \mathrm{~S}\right)^{(9)}$. Peningkatan bahan organik di waduk berkaitan dengan tataguna lahan di sekitarnya dan aktivitas dalam waduk ${ }^{(20)}$.
Berdasarkan PP No. 82 tahun 2001 kelas III, nilai sulfida dari ketiga perlakuan tidak memenuhi baku mutu untuk kegiatan budidaya perikanan tawar (baku mutu sulfida 0,002 $\mathrm{mg} / \mathrm{l})$. Namun mengingat adanya parameter lain seperti $\mathrm{DO}$, suhu, dan $\mathrm{pH}$ yang mampu menyokong kelangsungan hidup ikan budidaya di keramba jaring apung, maka relatif tingginya konsentrasi sulfida tersebut masih dapat ditolerir oleh ikan.

Jika kondisi seperti ini diiringi dengan miskin oksigen maka ikan budidaya pada keramba jaring apung cenderung akan mati, karena tidak mampu meloloskan diri dari kondisi kualitas air yang buruk. Fenomena demikianlah yang biasanya terjadi ketika terjadi umbalan dan berakibat fatal berupa kematian massal ikan di lokasi keramba jaring apung.

Salah satu cara yang mungkin bisa ditempuh, ketika diketahui perairan mengalami umbalan, dan ikan terlihat seperti kekurangan oksigen dan cenderung berada di permukaan air, adalah dengan menambah aerasi atau menarik keramba apung menjauhi lokasi umbalan.

\section{KESIMPULAN}

Konsentrasi DO di lokasi KJAdi Waduk Cirata cenderung menurun seiring bertambahnya kedalaman dengan kisaran rata-rata pada stasiun 1 adalah $0,5 \mathrm{mg} / 1$ (lapisan dasar) hingga 8,4 mg/l (permukaan). Pada stasiun 2 adalah $0,3 \mathrm{mg} / \mathrm{l}$ (lapisan dasar) hingga $8,0 \mathrm{mg} / 1$ (permukaan). Distribusi vertikal oksigen terlarut menggambarkan tipe perairan clinograde. Tidak ditemukan lapisan termoklin pada lokasi pengamatan. Kedalaman zona eufotik mencapai 3,81 m.

Terdapat variasi ketersediaan oksigen terlarut 
dari pencampuran massa air meromictic dan holomictic. Pada perlakuan 1 yang dianggap sebagai meromictic hingga kedalaman $12 \mathrm{~m}$, diperoleh nilai rata-rata DO yaitu $7,41 \mathrm{mg} / 1$ (stasiun 1) dan 7,00 mg/l (stasiun 2). Perlakuan 2 sebagai meromictic hingga kedalaman $24 \mathrm{~m}$ memiliki nilai DO rata-rata $5,48 \mathrm{mg} / 1$ (stasiun 1) dan 5,28 mg/l (stasiun 2). Perlakuan 3 yang dianggap sebagai pencampuran air sempurna (holomictic) hingga kedalaman $42 \mathrm{~m}$ memiliki nilai DO rata-rata $2,84 \mathrm{mg} / \mathrm{l}$ (stasiun 1) dan 2,44 mg/l (stasiun 2).

Berdasarkan konsentrasi oksigen terlarut disimpulkan bahwa jika terjadi percampuran meromictic hingga kedalaman $12 \mathrm{~m}$ dan $24 \mathrm{~m}$ maka kegiatan budidaya ikan masih dianggap layak, karena DO masih lebih dari $5 \mathrm{mg} / \mathrm{l}$. Namun demikian, pencampuran holomictic mengakibatkan DO mendekati anoksik, sehingga tidak dapat menopang budidaya perikanan. Konsentrasi sulfida, semua jenis pencampuran massa air baik meromictic maupun holomictic dapat membahayakan kehidupan ikan budidaya.

Percampuran massa air holomictic memiliki potensi paling buruk bagi kegiatan perikanan, karena air dengan DO yang mencapai anoksik di sekitar dasar perairan dapat terangkat ke permukaan. Percampuran holomictic berlangsung manakala terjadi pembalikan massa air (umbalan) di sekitar KJA Waduk Cirata.

\section{DAFTAR PUSTAKA}

1. Fielding, M., Schwanenberg, D., Twight, D.J., Eikaas, H.S., Pinho, J.L.S. and Viera, J.M.P. 2010. DSS for Water Quality Management of Marna Reservoir System in Singapore. $9^{\text {th }}$ International Conference on Hydroinformatcs, Tianjin, China. $8 \mathrm{p}$.

2. Garno, Y. S. 2002. Dinamika dan Status Kualitas Air Waduk Multi Guna Cirata. Jurnal Sains dan Teknologi Indonesia. $4(4): 1-8$.

3. Mustapha, M.K. 2008. Assessment of the Water Quality of Oyum Reservoir, Offa, Nigeria, Using Selected PhysicoChemical Parameters. Turkish Journal of Fisheries and Aquatic Siences 8 : 309-319

4. Thomas, C.L., Powell, J.D., and Johnson, D.M. 2008. Is Reservoir Water Quality Important in Hydroelectric Power Generaton. Ferrum College, USA. 28 p.

5. Effendi, Y. M. 2008. KJA Waduk Jatiluhur Membutuhkan 4 Juta Ekor Ikan Bandeng. http:// www. Madina. com [22 November 2009].

6. Husen, M. 2000. Kelestarian Danau dan Waduk di DAS Citarum Potensi dan Ancaman. Prosiding Semiloka Nasional Pengelolaan dan Pemanfaatan Danau dan Waduk. Bandung, 7 November 2000. Halaman 61-73.

7. Hoybya, J., Iritz, L., Zheleznyak, M., Maderich, V., Demchenko, R., Dziuba, N., Donchitz, G., and Koshebutsky, V. 2002. Water Quality Modelling to Support the Operation of the Kakhovka Reservoir, Dnieper River, Ukraine. Proceedings of the Fifth International Conference on Hydroinformatics, Cardiff, UK. 946 - 951 p.

8. Tiri, A. and Boudoukha, A. 2010. Hydrochemical Analysis and Assessment of Surface Water Quality in Koudiat Medouar Reservoir, Algeria. European Journal of Scientific Research. Vol 41 No 2 : 273-285 p. 
9. Effendi, H. 2003. Telaah Kualitas Air Bagi Pengelolaan Sumberdaya Dan Lingkungan

10. Perairan. Kanisius. Jogjakarta. 258 hal.

11. Mullins, M.L. and Whisenant, A.S. 2004. Sommerville Reservoir Water Quality Study. Texas Parks and Wildlfe. $20 \mathrm{p}$.

12. Jain, S., Baumberger, L., Adams, S., Jackson, T. and Fuller, B. 2007. Offstream Reservoir: A Tool for Improving Yeld and water Quality Reliability. Florda Water Resources Journal. February 2007. p 22-25

13. Papadmitrakis, Y. and Fidikakis, A. 2005. An Integrated Approach to Water Quality Monitoring in Reservoirs, Aqueducts, and Distrbution Networks of Water Supply Systems. European Water 11/12: 27-34.

14. Graham, J.L., Loftin, K.A., Ziegler, A.C., and Meyer, M.T. 2008. Cyanobacteria $n$ Lakes and Reservoirs: Toxin and Taste and Odor Sampling Guidelines. U.S. Geological Survey TWRI Book 9. 65 p.

15. Garno, Y.S. 2001. Status dan Karakteristik Pencemaran di Waduk Kaskade Citarum. Jurnal Teknologi Lingkungan, 2 (2) : 207-213

16. Goldman, G. R. and Horne, A. J. 1983. Limnology. McGraw Hill Book Company. International Student Edition, Japan.

17. Prihadi, T. H. 2005. Pengelolaan Budidaya Ikan Secara Lestari di Waduk: Studi Kasus di Perairan Waduk Cirata Jawa Barat. Disertasi. Sekolah Pascasarjana IPB. Bogor. 226 hal.
18. Asante, K.A. Quarcopome, T. and Amevenku, F.Y.K. 2007. Water Quality of the Weija Reservoir after 28 Years of Impoundment. West African Journal of Applied Ecology. Vol 13.

19. Wax, P. 2006. Lake Water Quality Assessment for Pipestem Reservoir Stutsman County, North Dakota. North Dakota Depertment of Health. Divison of Water Quality. $15 \mathrm{p}$.

20. Garcia, F.C., Barbosa, F.A.R., Braz, S., Petrucio, M.M. and Faria, B. 2009. Water Quality of an Urban Reservoir Subjected to Periodic Applications of Copper Sulphate: the Case of Ibirite Reservoir, Southeast Brazil. Acta Limnol. Bras. Vol 21 No 2 p. 235 243.

21. Akintola, F.O. and Gbadegesin, A. 1997. Land-use Changes and Water Quality in Impounded WaterSupply Dams in Southwest Nigeria. Freshwater Contamination Proceeding of Rabat Symposium S4, IAHS. 